\title{
Low Diaphragm Muscle Mass Predicts Adverse Outcome in Patients Hospitalized for Covid-19 Pneumonia
}

\author{
Francesco Corradi ( $\nabla$ francesco.corradi@unipi.it ) \\ Università di Pisa https://orcid.org/0000-0002-5588-2608
}

\section{Alessandro Isirdi \\ Universita degli Studi di Pisa}

\section{Claudia Brusasco}

Ente Ospedaliero Ospedali Galliera

\section{Gregorio Santori}

Universita degli Studi di Genova

\section{Marco Falcone}

Universita degli Studi di Pisa

\section{Luna Gargani}

"Consiglio Nazionale delle Ricerche"

\section{Chiara Romei}

Ospedale Cisanello

\section{Greta Barbieri}

Universita degli Studi di Pisa

\section{Fabio Guarracino}

Ospedale Cisanello

\section{Luigi Vetrugno}

Universita degli Studi di Udine

Giovanni Landoni

Ospedale San Raffaele

\section{Francesco Forfori}

Universita degli Studi di Pisa

\section{Research}

Keywords: Diaphragmatic Thickness, Diaphragm Ultrasound, Acute Respiratory Failure, point-of-care ultrasonography

Posted Date: August 4th, 2020

DOI: https://doi.org/10.21203/rs.3.rs-52246/v1 
License: (a) (i) This work is licensed under a Creative Commons Attribution 4.0 International License. Read Full License 


\section{Abstract}

Purpose: The aim of this study was to evaluate whether measurement of diaphragm thickness by ultrasonography may be a clinically useful noninvasive method for identifying patients at risk of adverse outcomes defined as need of invasive mechanical ventilation or death.

Methods: We retrospectively reviewed the records of consecutive of 77 patients with laboratory-confirmed Covid-19 infection admitted to our intermediate care unit in Pisa between March 5 and March 30, 2020, with follow up until hospital discharge or death. Logistic regression was used identify variables potentially associated with adverse outcomes and those $\mathrm{P}<0.10$ were entered into a multivariate logistic regression model. Cumulative probability for lack of adverse outcomes in patients with or without low baseline diaphragm muscle mass was calculated with the Kaplan-Meier product-limit estimator.

Results: The main findings of this study are that 1) patients who developed adverse outcomes had thinner diaphragm than those who did not (2.0 vs $2.2 \mathrm{~mm}, \mathrm{p}: 0.001)$, 2) DT and lymphocyte count were independent significant predictors of adverse outcomes, with end-expiratory DT being the strongest (怄-708, OR: 0.492, p: 0.018).

Conclusion: Diaphragmatic ultrasound may be a valid tool to evaluate the risk of respiratory failure. Evaluating the need of mechanical ventilation treatment should be based not only on $\mathrm{PaO}_{2} / \mathrm{FiO}_{2}$, but on a more comprehensive assessment including DT because if the lungs become less compliant a thinner diaphragm, albeit free of intrinsic abnormality, may become exhausted, thus contributing to severe respiratory failure.

\section{Introduction}

The outbreak of Covid-19 has revealed a new kind of acute respiratory failure with unique pathophysiological and clinical features. At hospital admission, most patients show a dissociation between the severity of hypoxemia and a relatively preserved respiratory mechanics. This early stage of the disease is mainly characterized from a morphological point of view by interstitial edema, ${ }^{1}$ which appears as a ground-glass pattern on chest computer tomography (CT), and from a clinical point-of-view by an increased breathing frequency with only mild or no dyspnea. With disease progression, some patients become severely dyspneic and unable to sustain adequate ventilation by the action of their inspiratory muscles.

The aim of this study was to evaluate whether measurement of diaphragm thickness (DT) ${ }^{2}$ by ultrasonography may be a clinically useful noninvasive method for identifying patients at risk of adverse outcomes, i.e., need of invasive mechanical ventilation (IMV) or death.

\section{Methods}

The local ethics committee approved the study, waiving written consent owing to the observational design and the urgent need for patient care and data collection. (CEAVNO 2020/17133 COVID-LUS). 
We retrospectively reviewed the records of consecutive patients with laboratory-confirmed Covid-19 infection admitted to our intermediate care unit in Pisa between March 5 and March 30, 2020, with follow up until hospital discharge or death. At hospital admission, patients underwent screening swab for SARS-Covid-2 and chest radiography or computed tomography (CT) for diagnostic purposes. The diagnosis of Covid-19 was confirmed by a positive reverse-transcriptase-polymerase-chain-reaction (RT-PCR) assay of a specimen collected on a nasopharyngeal swab with radiological evidence of interstitial lung involvement.

An intensivist evaluated all patients with respiratory failure, and those considered not requiring IMV were admitted to intermediate care wards. Criteria for starting IMV were the following: persistence of severe respiratory failure with $\mathrm{PaO}_{2} / \mathrm{FIO}_{2}<200$, respiratory rate $>30$, and/or clinical signs of respiratory exhaustion. Patients receiving oxygen therapy were managed in order to achieve a SpO2 target of $92 \%$ by adjusting $\mathrm{FIO}_{2}$.

All patients underwent diaphragm ultrasonography within 36 hours from admission in order to measure DT in the zone of apposition. The linear probe was placed above the right $10^{\text {th }}$ rib on the mid-axillary line. Endexpiratory DT was measured on two consecutive breaths from two separate images. ${ }^{3}$ Measurements were repeated until three values consistent within $10 \%$ were obtained and their mean was retained for analysis. Patients were followed-up until hospital discharge or IMV/death.

\section{Statistical Analysis}

All variables are expressed as median (IQR) or percentage (\%). Mann Whitney U-test or Fisher's exact test, were used to evaluate differences between groups, i.e., with favorable or unfavorable outcome. Spearman correlation coefficient was used to test correlations between variables. Logistic regression was used identify variables potentially associated with adverse outcomes and those $\mathrm{P}<0.10$ were entered into a multivariate logistic regression model. Cumulative probability for lack of adverse outcomes in patients with or without low baseline diaphragm muscle mass was calculated with the Kaplan-Meier product-limit estimator. The end of follow-up for censored/uncensored patients corresponded to hospital discharge/occurrence of complication. The log-rank (Mantel-Cox) test was applied to evaluate the difference in probability for lack of complications after grouping for low baseline diaphragm muscle mass or not. Statistical significance was assumed at $\mathrm{P}<0.05$, two-tailed null hypothesis. SPSS (version 20.0; SPSS Inc, Chicago, III) and R environment (version 3.6.3; R Foundation for Statistical Computing, Vienna, Austria) were used.

\section{Results}

\section{Patients}

Over the study period, we treated 77 consecutive in the intermediate care wards (infectious diseases and pulmonology). Their clinical characteristics, laboratory data and imaging findings at admission are summarized in Table 1. A chest radiograph was obtained in 35 patients $(46 \%)$, showing bilateral pulmonary opacities; chest CT was obtained in 50 patients $(65 \%)$, consistently showing bilateral ground-glass opacities without pleural effusions. 
The median lung attenuation was $-772 \mathrm{HU}(-822$ to -709$)$, indicating moderate-to-severe lung involvement, which was not significantly different between the patients who recovered and those who died or were intubated $(-776$ vs $-765 \mathrm{HU}, \mathrm{p}=0.173)$. Median (IQR) diaphragmatic thickness was $2.2(2.0-2.2) \mathrm{mm}$. The diaphragm was slightly thinner in females than males (2.1 [1.9-2.2] vs 2.2 [2.1-2.2] $p=0.011)$, as expected, and in cancer compared with non-cancer patients $(2.0$ [1.8-2.2] vs 2.2 [2.0-2.2] $p=0.020)$. DT was not correlated with age, body mass index, median lung density, lung weight, $\mathrm{PO}_{2} / \mathrm{FiO}_{2}$, history of chronic obstructive lung disease, cardiovascular disease, diabetes, chronic kidney disease, or cerebrovascular disease.

\section{Outcomes}

Sixty-two patients (81\%) successfully recovered and were discharged with a median length of stay of 17 (1029 ) days. Fifteen patients (19\%) eventually required IMV or died. Ten patients out of twelve subjects who died, had a "do-not-resuscitate order"(DNR) instituted at admission due to concomitant presence of multiple frailties defined as age $>80$ years, concomitant chronic organ failures (cardiac, renal, respiratory) and/or active cancer. The overall mortality observed was $15.6 \%$ including the overall 21 DNR patients. Notably, $11 / 21$ (48\%) patients meeting the DNR criteria, recovered. Excluding patients with "DNR-order" the overall mortality was $3.6 \%$.

\section{Prediction models}

The full model evaluated by entering all predictors was statistically significant, indicating that the model was able to distinguish between patients with and without adverse outcomes. The model as a whole explained between $44 \%$ (Cox and Snell $\mathrm{R}^{2}$ ) and $68 \%$ (Nagelkerke $\mathrm{R}^{2}$ ) of the variance in outcomes and correctly classified $95 \%$ of cases. Only two of the independent variables made a unique statistically significant contribution to the model (lymphocyte count and end-expiratory diaphragmatic thickness), being the end-expiratory diaphragmatic thickness the strongest (怄-708, OR: 0.492, p: 0.018) (Table 2). DT was entered into ROC curve analysis to determine The best threshold value for DT assessed by receiver operator curve analysis was $<2.2 \mathrm{~mm}$ (AUOC: $0.791, \mathrm{Cl}: 0.676-0.907, \mathrm{p}: 0.001$ ). A statistically significant difference ( $\mathrm{p}$ $<0.001$ ) was observed in the Kaplan-Meyer plots for cumulative adverse outcomes between patients with or without low baseline diaphragm muscle mass defined as DT <2.2mm (Figure 1).

\section{Discussion}

The main findings of this study are that 1) patients who developed adverse outcomes had thinner diaphragm than those who did not, 2) DT and lymphocyte count were independent significant predictors of adverse outcomes, with end-expiratory DT being the strongest. Because of its geometry, DT is linearly correlated with its cross-sectional area ${ }^{4}$ and, hence, mass. ${ }^{5}$ This study was based on the concept that low diaphragm mass may limit the strength of the inspiratory pump, thus facilitating progression from mild to severe respiratory failure eventually requiring IMV, in case of worsening pneumonia where the respiratory system becomes less compliant. Indeed, we found that even when vital signs were stable at hospital arrival, an end-expiratory $\mathrm{DT}<2.2 \mathrm{~mm}$ should be considered as a risk factor for respiratory exhaustion. On the 
contrary, $\mathrm{PaO}_{2} / \mathrm{FiO}_{2}$, though significantly different between patients with or without adverse outcomes (300 [253-300] vs 250 [200-300] $p=0.038$ ), was not able to predict the primary endpoint.

The observed association between end-expiratory DT and clinical outcomes might be explained by the fact that a thinner diaphragm may not be able to sustain ventilation in the face of increasing inspiratory loads. Therefore, in the event that the lung becomes less compliant even patients with non-pathological diaphragms but with a relatively lower muscle mass, could more easily experience respiratory fatigue.

These findings may have implications for clinical practice. Being low DT independently associated with risk IMT or death, it may be used to prompt interventions in order to prevent the evolution of respiratory failure as well as implementing strategies aimed at preserving diaphragm muscle mass (e.g., nutritional support).

This study have limitations. First, it was conducted in a small number of spontaneously breathing noncritically ill patients. Second, parameters and settings of ultrasound device affect DT measurements, which makes our cutoff values not generalizable. Thus, our results are to be taken as a proof-of-concept for a larger study.

\section{Conclusion}

Diaphragmatic ultrasound may be a valid tool to evaluate the risk of respiratory failure. Evaluating the need of mechanical ventilation treatment should be based not only on $\mathrm{PaO}_{2} / \mathrm{FiO}_{2}$, but on a more comprehensive assessment including DT because if the lungs become less compliant a thinner diaphragm, albeit free of intrinsic abnormality, may become exhausted, thus contributing to severe respiratory failure.

\section{Declarations}

A. Ethics approval and consent to participate: The local ethical committee approved the study (CEAVNO 2020/17133 COVID-LUS) waiving written consent owing to the observational design and the urgent need for patient care and data collection.

B. Consent for publication: "Not applicable". The manuscript does not contain any individual person's data.

C. Availability of data and material: The dataset analyzed during the current study is available from the corresponding author on reasonable request.

D. Funding: "Not applicable"

E. Authors contributions: FC, FF had full access to all the data in the study and takes responsibility for the integrity of the data and the accuracy of the data analysis. $\mathrm{CB}, \mathrm{FF}, \mathrm{Al}$, and $\mathrm{FC}$ were responsible for the study concept and design. FF, MF, CR, GB, and FC were responsible for the acquisition, analysis, or interpretation of data. $C B, G L, F G, L V$, and $F C$ were responsible for the drafting of the manuscript. $F F, L G$, LV, GL, GB, Al, GS, CB, GS, FC were responsible for the critical revision of the manuscript for important intellectual content. FC and GS were responsible for the statistical analysis. CB, Al, CR, GB, FF and FC were responsible for the administrative, technical, or material support. FC was responsible for the study supervision. All authors read and approved the final manuscript 
F. Acknowledgements: All the participants of the UCARE have contributed to the preparation of the manuscript and have approved it. ${ }^{*}$ The collaborators of the Ultrasound in Critical care and Anesthesia Research Group (UCARE) are listed in alphabetical order: Pietro Bertini, Nicoletta Carpenè, Laura Carrozzi, Alessandro Celi, Virginia Chirici, Francesco Cundari, Diego Costanzo, Alessandra Della Rocca, Salvatore DeMarco, Massimo Desideri, Lorenzo Ghiadoni, Alberto Laffi, Paolo Malacarne, Francesco Menichetti, Marco Monfroni, Fabio Monzani, Chiara Piagnani, Massimo Santini, Ludovica Tecchi, Giusy Tiseo, Agostino Virdis.

G. Competing interests: The authors declare that they have no competing interests.

\section{References}

1. Bernheim A, Mei X, Huang M, et al. Chest CT Findings in Coronavirus Disease-19 (COVID-19): Relationship to Duration of Infection. Radiology 2020;295(3):200463.

2. Tuinman PR, Jonkman AH, Dres $M$, et al. Respiratory muscle ultrasonography: methodology, basic and advanced principles and clinical applications in ICU and ED patients-a narrative review. Intensive Care Med 2020;46(4):594-605.

3. Sklar MC, Dres M, Fan E, et al. Association of Low Baseline Diaphragm Muscle Mass With Prolonged Mechanical Ventilation and Mortality Among Critically III Adults. JAMA Netw Open 2020;3(2):e1921520.

4. McCool FD, Benditt JO, Conomos P, Anderson L, Sherman CB, Hoppin FG. Variability of diaphragm structure among healthy individuals. Am J Respir Crit Care Med 1997;155(4):1323-8.

5. Arora NS, Rochester DF. Effect of body weight and muscularity on human diaphragm muscle mass, thickness, and area. J Appl Physiol Respir Environ Exerc Physiol 1982;52(1):64-70.

\section{Tables}

Table 1. Clinical characteristics, laboratory data and imaging findings at hospital admission. 


\begin{tabular}{|c|c|c|c|c|}
\hline Characteristics & $\begin{array}{l}\text { All patients } \\
\text { (77) }\end{array}$ & Alive (62) & $\begin{array}{l}\text { Dead or intubated } \\
\text { (15) }\end{array}$ & $\mathrm{p}$ \\
\hline Age (years) & $59(51-77)$ & $58(49-69)$ & $78(59-82)$ & 0.002 \\
\hline Male sex & $51(66)$ & $40(65)$ & $11(73)$ & 0.762 \\
\hline $\begin{array}{l}\text { Length of symptoms before } \\
\text { admission (days) }\end{array}$ & $6(2-10)$ & $7(4-10)$ & $2(0-4)$ & 0.004 \\
\hline \multicolumn{5}{|l|}{ Vital signs } \\
\hline Temperature $\left({ }^{\circ} \mathrm{C}\right)$ & 38 (37.8-38.3) & $38(37.8-38.1)$ & $38(37.7-38.5)$ & 0.733 \\
\hline Heart rate $(\mathrm{bpm})$ & $85(75-97)$ & $83(74-95)$ & $97(76-100)$ & 0.101 \\
\hline Respiratory rate & $20(18-26)$ & $20(18-25)$ & $22(18-26)$ & 0.495 \\
\hline Systolic blood pressure (mmHg) & $\begin{array}{l}137(120- \\
148)\end{array}$ & $\begin{array}{l}136(123- \\
148)\end{array}$ & $140(120-148)$ & 0.882 \\
\hline Diastolic blood pressure $(\mathrm{mmHg})$ & $80(70-90)$ & $80(71-90)$ & $90(70-92)$ & 0.587 \\
\hline $\mathrm{PaO} 2 / \mathrm{FiO} 2$ ratio & $\begin{array}{l}290(233- \\
300)\end{array}$ & $\begin{array}{l}300(253- \\
300)\end{array}$ & $250(200-300)$ & 0.038 \\
\hline \multicolumn{5}{|l|}{ Laboratory Data } \\
\hline White-cell (x 109/L) & $\begin{array}{l}6.11(4.65- \\
7.92)\end{array}$ & $\begin{array}{l}6.02(4.56- \\
8.24)\end{array}$ & $6.97(4.75-7.58)$ & 0.912 \\
\hline Lymphocyte (x 109/L) & $\begin{array}{l}1.06(0.69- \\
1.33)\end{array}$ & $\begin{array}{l}1.10(0.70- \\
1.36)\end{array}$ & $0.85(0.54-1.17)$ & 0.037 \\
\hline Aspartate aminotransferase (U/L) & $32(26-43)$ & $32(26-42)$ & $32(24-90)$ & 0.830 \\
\hline Alanine aminotransferase (U/L) & $27(20-49)$ & $30(21-49)$ & $21(14-50)$ & 0.163 \\
\hline Serum creatinine (mg/dL) & $\begin{array}{l}1.02(0.88- \\
1.24)\end{array}$ & $\begin{array}{l}1.00(0.86- \\
1.13)\end{array}$ & $1.24(1-2.57)$ & 0.022 \\
\hline Troponin (ng/L) & $10(6-24)$ & $9(6-17)$ & $36(21-86)$ & 0.001 \\
\hline Platelet count $\left(10^{3} / \mathrm{mcL}\right)$ & $\begin{array}{l}165(132- \\
200)\end{array}$ & $\begin{array}{l}166(139- \\
201)\end{array}$ & $163(125-201)$ & 0.553 \\
\hline Bilirubin level (mg/dL) & $\begin{array}{l}0.54(0.38- \\
0.89)\end{array}$ & $\begin{array}{l}0.54(0.38- \\
0.93)\end{array}$ & $0.63(0.38-0.71)$ & 0.983 \\
\hline Creatine kinase level $(\mathrm{U} / \mathrm{L})$ & $115(55-230)$ & $111(50-236)$ & $120(55-360)$ & 0.984 \\
\hline Arterial lactate (mg/dL) & $1.2(0.9-2.4)$ & $0.9(0.8-2.4)$ & $1.85(1-3.3)$ & 0.230 \\
\hline Procalcitonin (ng/mL) & $\begin{array}{l}0.09(0.06- \\
0.21)\end{array}$ & $\begin{array}{l}0.08(0.06- \\
0.19)\end{array}$ & $0.1(0.09-0.54)$ & 0.206 \\
\hline $\mathrm{C}$ reactive protein $(\mathrm{mg} / \mathrm{L})$ & $\begin{array}{l}4.19(2.12- \\
6.65)\end{array}$ & $4.3(2.4-10.8)$ & $5.95(2.65-9.42)$ & 0.341 \\
\hline D-Dimer (mg/L) & $0.57(0.23-$ & $0.49(0.22-$ & $0.79(0.58-0.79)$ & 0.476 \\
\hline
\end{tabular}



0.99)
0.95

Quantitative CT

Mean lung density (HU)

$-772(-822 /$

$-775(-833 /$

$-715(-812 /-660)$

0.173

-709)

$-725)$

Lung weight (grams)

957 (829-

957 (828-

958 (872-1329)

0.682

1159)

1159)

Diaphragmatic US

End-expiratory DT (mm)

$2.2(2.0-2.2)$

$2.2(2.2-2.2)$

$2.0(1.9-2.1)$

0.0012

Data are median with interquartile range (IQR) or absolute numbers (\%). $\mathrm{Bpm}$, beats per minute; $\mathrm{PaO}_{2} / \mathrm{FiO}_{2}$, ratio of arterial oxygen pressure to inspired oxygen fraction breathing room air; $\mathrm{CT}$, chest tomography; $\mathrm{HU}$, Hounsfield Units; US, ultrasound; DT, diaphragmatic thickness.

Table 2. Univariate and multivariate logistic regression of potential predictive parameters at hospital admission for oro-tracheal intubation or death. 


\begin{tabular}{|c|c|c|c|c|c|c|c|c|}
\hline Parameter & $\begin{array}{l}\text { Univariate } \\
\text { analysis }\end{array}$ & $\begin{array}{l}\text { Multivariate } \\
\text { analysis }\end{array}$ & & & & & & \\
\hline & b & OR & $95 \% \mathrm{Cl}$ & $\mathrm{p}$ & $b$ & OR & $95 \% \mathrm{Cl}$ & $\mathrm{p}$ \\
\hline Age & 0.077 & 1.081 & $\begin{array}{l}1.032- \\
1.141\end{array}$ & 0.002 & 0.105 & 1.111 & $\begin{array}{l}1.010- \\
1.259\end{array}$ & 0.051 \\
\hline Sex (male) & 0.414 & 1.512 & $\begin{array}{l}0.430- \\
5.317\end{array}$ & 0.519 & & $\begin{array}{l}\text { Not } \\
\text { entered }\end{array}$ & & \\
\hline $\begin{array}{l}\text { Days of } \\
\text { Symptoms } \\
\text { before admission }\end{array}$ & -0.227 & 0.797 & $\begin{array}{l}0.654- \\
0.932\end{array}$ & 0.010 & -0.261 & 0.770 & $\begin{array}{l}0.554- \\
0.989\end{array}$ & 0.068 \\
\hline Temperature & 0.168 & 1.183 & $\begin{array}{l}0.441- \\
3.177\end{array}$ & 0.739 & & $\begin{array}{l}\text { Not } \\
\text { entered }\end{array}$ & & \\
\hline Heart rate & -0.033 & 0.968 & $\begin{array}{l}0.927- \\
1.010\end{array}$ & 0.138 & & $\begin{array}{l}\text { Not } \\
\text { entered }\end{array}$ & & \\
\hline Respiratory rate & -0.027 & 0.973 & $\begin{array}{l}0.885- \\
1.071\end{array}$ & 0.580 & & $\begin{array}{l}\text { Not } \\
\text { entered }\end{array}$ & & \\
\hline $\begin{array}{l}\text { Systolic blood } \\
\text { pressure }\end{array}$ & 0.011 & 1.011 & $\begin{array}{l}0.982- \\
1.042\end{array}$ & 0.457 & & $\begin{array}{l}\text { Not } \\
\text { entered }\end{array}$ & & \\
\hline $\begin{array}{l}\text { Diastolic blood } \\
\text { pressure }\end{array}$ & -0.017 & 0.983 & $\begin{array}{l}0.942- \\
1.025\end{array}$ & 0.424 & & $\begin{array}{l}\text { Not } \\
\text { entered }\end{array}$ & & \\
\hline $\mathrm{PaO}_{2} / \mathrm{FiO}_{2}$ ratio & -0.012 & 0.989 & $\begin{array}{l}0.977- \\
0.998\end{array}$ & 0.030 & -0.007 & 0.993 & $\begin{array}{l}0.972- \\
1.011\end{array}$ & 0.470 \\
\hline White-cell count & 0.001 & 1.001 & $\begin{array}{l}0.833- \\
1.203\end{array}$ & 0.992 & & $\begin{array}{l}\text { Not } \\
\text { entered }\end{array}$ & & \\
\hline $\begin{array}{l}\text { Lymphocyte } \\
\text { count }\end{array}$ & -0.002 & 0.998 & $\begin{array}{l}0.997- \\
1.000\end{array}$ & 0.059 & -0.002 & 0.998 & $\begin{array}{l}0.995- \\
1.000\end{array}$ & 0.046 \\
\hline $\begin{array}{l}\text { Aspartate } \\
\text { aminotransferase }\end{array}$ & -0.012 & 0.988 & $\begin{array}{l}0.969- \\
1.007\end{array}$ & 0.201 & & $\begin{array}{l}\text { Not } \\
\text { entered }\end{array}$ & & \\
\hline $\begin{array}{l}\text { Alanine } \\
\text { aminotransferase }\end{array}$ & 0.012 & 1.012 & $\begin{array}{l}0.990- \\
1.035\end{array}$ & 0.292 & & $\begin{array}{l}\text { Not } \\
\text { entered }\end{array}$ & & \\
\hline Serum creatinine & -0.315 & 0.730 & $\begin{array}{l}0.481- \\
1.107\end{array}$ & 0.139 & & $\begin{array}{l}\text { Not } \\
\text { entered }\end{array}$ & & \\
\hline Troponin & 0.011 & 1.012 & $\begin{array}{l}1.002- \\
1.027\end{array}$ & 0.071 & -0.005 & 1.005 & $\begin{array}{l}0.993- \\
1.026\end{array}$ & 0.592 \\
\hline Platelet count & 0.002 & 1.002 & $\begin{array}{l}0.994- \\
1.011\end{array}$ & 0.580 & & $\begin{array}{l}\text { Not } \\
\text { entered }\end{array}$ & & \\
\hline Bilirubin level & 0.038 & 1.039 & $\begin{array}{l}0.752- \\
1.435\end{array}$ & 0.817 & & $\begin{array}{l}\text { Not } \\
\text { entered }\end{array}$ & & \\
\hline $\begin{array}{l}\text { Creatine kinase } \\
\text { level }\end{array}$ & 0.001 & 1.000 & $\begin{array}{l}0.996- \\
1.004\end{array}$ & 0.992 & & $\begin{array}{l}\text { Not } \\
\text { entered }\end{array}$ & & \\
\hline
\end{tabular}




\begin{tabular}{|c|c|c|c|c|c|c|c|c|}
\hline Arterial lactate & -0.870 & 0.419 & $\begin{array}{l}0.098- \\
1.799\end{array}$ & 0.242 & & $\begin{array}{l}\text { Not } \\
\text { entered }\end{array}$ & & \\
\hline Procalcitonin & -0.722 & 0.486 & $\begin{array}{l}0.162- \\
1.455\end{array}$ & 0.197 & & $\begin{array}{l}\text { Not } \\
\text { entered }\end{array}$ & & \\
\hline$C$ reactive protein & -0.025 & 0.975 & $\begin{array}{l}0.902- \\
1.054\end{array}$ & 0.524 & & $\begin{array}{l}\text { Not } \\
\text { entered }\end{array}$ & & \\
\hline D-Dimer & 0.183 & 1.200 & $\begin{array}{l}0.321- \\
4.496\end{array}$ & 0.786 & & $\begin{array}{l}\text { Not } \\
\text { entered }\end{array}$ & & \\
\hline $\begin{array}{l}\text { CT Mean lung } \\
\text { density }\end{array}$ & -0.002 & 0.998 & $\begin{array}{l}0.985- \\
1.011\end{array}$ & 0.735 & & $\begin{array}{l}\text { Not } \\
\text { entered }\end{array}$ & & \\
\hline CT Lung weight & 0.001 & 1.000 & $\begin{array}{l}0.996- \\
1.003\end{array}$ & 0.848 & & $\begin{array}{l}\text { Not } \\
\text { entered }\end{array}$ & & \\
\hline $\begin{array}{l}\text { End-expiratory } \\
\text { DT }\end{array}$ & -0.474 & 0.623 & $\begin{array}{l}0.433- \\
0.842\end{array}$ & 0.005 & -0.708 & 0.492 & $\begin{array}{l}0.241- \\
0.818\end{array}$ & 0.018 \\
\hline
\end{tabular}

b, indicates regression coefficients; $\mathrm{Cl}$, confidence intervals; $\mathrm{OR}$, odd ratio; $\mathrm{PaO}_{2} / \mathrm{FiO}_{2}$, ratio of arterial oxygen pressure to inspired oxygen fraction breathing room air; $\mathrm{CT}$, chest tomography; DT, diaphragmatic thickness.

Figures 


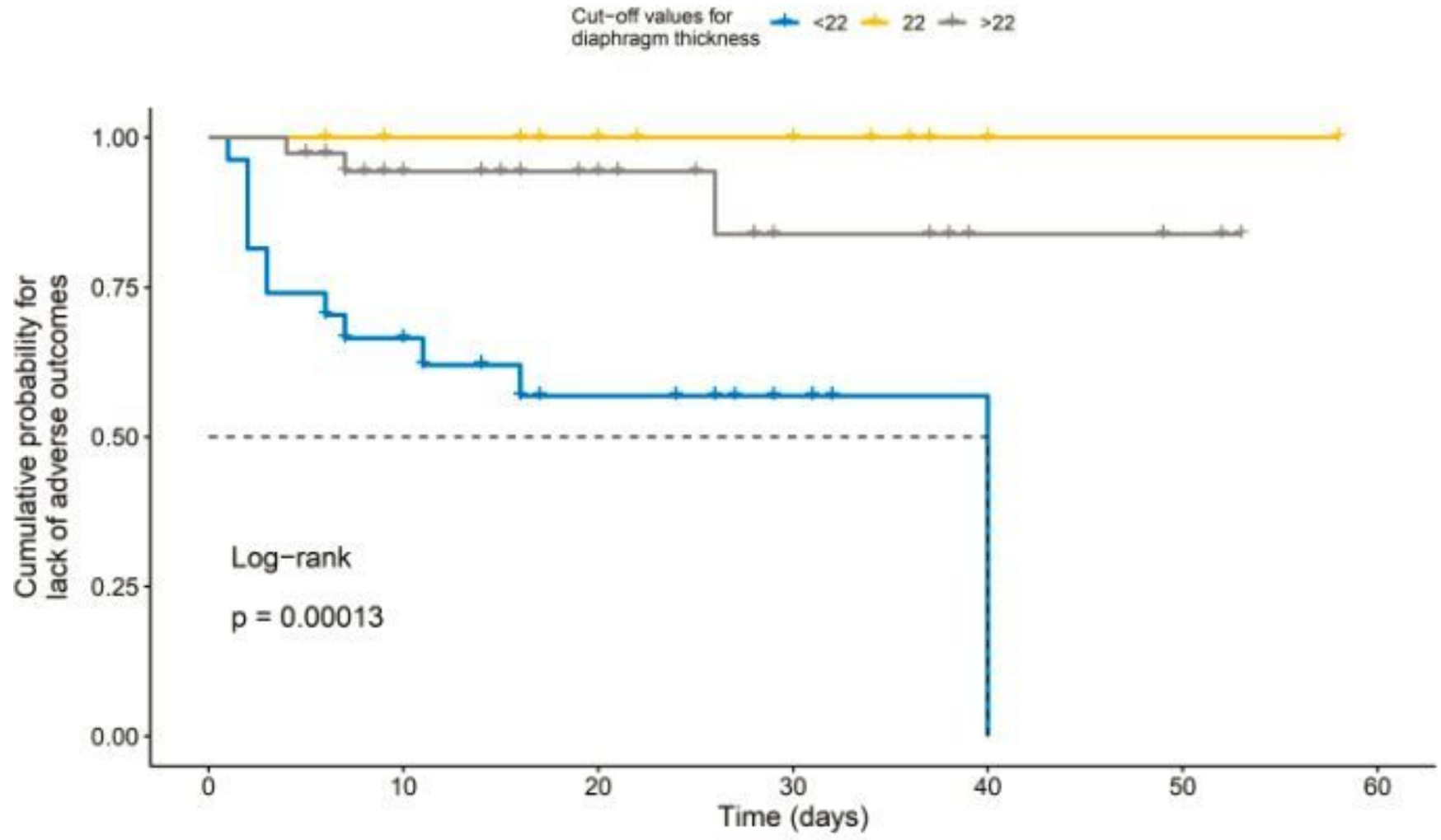

Number at risk

$\begin{array}{rrrrrrr}-27 & 16 & 8 & 3 & 1 & 0 & 0 \\ -\quad 12 & 10 & 8 & 6 & 2 & 1 & 0 \\ -38 & 25 & 13 & 6 & 3 & 2 & 0\end{array}$

\section{Cumulative number of events}

$\begin{array}{ccccccc}-0 & 9 & 11 & 11 & 12 & 12 & 12 \\ - & 0 & 0 & 0 & 0 & 0 & 0 \\ 0 & 2 & 2 & 3 & 3 & 3 & 3\end{array}$

Figure 1

Comparison of the Kaplan-Meier curves for lack of adverse outcomes (IMV or death) in patients with a diaphragmatic thickness higher, equal or lower than $2.2 \mathrm{~mm}$ by using the log-rank test $(p=<0.001)$. The number of patients at each time point is shown as a mark on the corresponding line. Patients were censored at hospital discharge. 